\title{
MODELO FONTE PARA LIBERAÇÃO DE CO COMBINADO A HSM (HYBRID SWTICH MODEL) IMPLEMENTADO NO OPENFOAM PARA CASOS DE LIBERAÇÃO ACIDENTAL
}

\author{
T. R. RODRIGUES, R. R. C. SANTOS, S. S. V. VIANNA \\ Universidade Estadual de Campinas, Faculdade de Engenharia Química \\ E-mail para contato: savio@feq.unicamp.br
}

\begin{abstract}
RESUMO - Simulações numéricas são bastante utilizadas na área de análise de consequência. A análise consiste na utilização de equações matemáticas para descrever fenômenos reais. Neste caso, fenômenos relacionados a vazamento de líquido ou gás, explosão e incêndio. Uma ferramenta promissora para análise de consequência é o OpenFOAM, pacote de código aberto e gratuito, programado em $\mathrm{C}++$. Neste trabalho, foi utilizado o OpenFOAM para simular uma situação de vazamento e dispersão de dióxido de carbono. O interesse na análise de risco para o gás carbônico é devido a implementação de tecnologias para captura e estocagem de carbono bem como as reservas de óleo e gás do pré-sal, as quais possuem uma quantidade significativa de gás carbônico associado. $\mathrm{O}$ trabalho mostra que o OpenFOAM é uma ferramenta promissora para análise de risco, por apresentar resultados concordantes com a literatura, além de proporcionar a modificação do código fonte. Os resultados com as simulações mostraram concordância com os dados da literatura.
\end{abstract}

\section{INTRODUÇÃO}

Face às legislações de liberação de dióxido de carbono e contaminantes à atmosfera, empresas são obrigadas a realizar a captura de dióxido de carbono $\left(\mathrm{CO}_{2}\right)$. Plantas de processamento de $\mathrm{CO}_{2}$ são construídas em plataformas de petróleo e gás e unidades flutuantes de armazenamento e transferência (FPSO). Nesse caso, o principal objetivo em recuperar $\mathrm{CO}_{2}$ está em reinjetá-lo aos poços para extração de óleo. Outras indústrias, principalmente de geração de energia (grandes produtoras de $\mathrm{CO}_{2}$ ) são obrigadas a estocar ou transportá-lo destinando a outros fins.

O meio mais viável economicamente para transporte de $\mathrm{CO}_{2}$ é por meio de tubulações, transferindo o dióxido de carbono na fase líquida ou supercrítica, ou seja altas pressões e temperatura próximas a ambiente.

Um dos riscos em plantas e linhas de transporte de $\mathrm{CO}_{2}$ consiste no vazamento do mesmo. $\mathrm{O} \mathrm{CO}_{2}$ apresenta toxicidade elevada, apresentada por Harper et al. (2011) e valores de SLOD ( probabilidade significativa de morte) e SLOT (probabilidade significativa de toxicidade) próximos. Mostra também que concentração acima de 7\% apresenta risco elevado para seres humanos. A quantidade de $\mathrm{CO} 2$ transportada é da escala de toneladas, apresentando 
risco significativo para a vida de trabalhadores em plantas de processo e moradores, no caso de linhas de transporte próximas a áreas urbanas.

Para projeto de planta de processo, plataforma e linhas de tubulação próximas as áreas urbanas são realizadas análise de consequência, que consistem no estudo da área vulnerável devido a rupturas e vazamentos. Atualmente, fluidodinâmica computacional (CFD) é a ferramenta mais utilizada para esses estudos, segundo Mazzoldi, et al. (2011). É possível calcular a concentração do gás diante de um possível vazamento, a partir do seu escoamento. O escoamento é simulado utilizando as equações de conservação (massa, quantidade de movimento e energia). Além disso, as simulações apresentam maior confiabilidade já que levam em conta equações de transporte, propriedades termodinâmicas e fatores externos (fatores climáticos, obstáculos e relevo do ambiente), bem como o efeito do terreno e da geometria.

A maioria dos programas para análise risco e simuladores CFD são comerciais, apresentando custo elevado, exemplo do FLACS, PHAST, FLUENT, CFX. Uma alternativa as esses softwares é o OpenFOAM (Open source Field Operation And Manipulation), o qual é um pacote gratuito e de código aberto escrito em $\mathrm{C}++$, para resolução de equações diferenciais parciais utilizando método de volumes finitos. Possui solvers, que são modificações do código para casos específicos, como fluidos incompressíveis, compressíveis, reações químicas, combustão, entre outros. Possui modelos de turbulência e condições de contorno. A vantagem do OpenFOAM é que por ser aberto é possível modificar o código para desenvolvimento de novos solvers, por exemplo, um específico para área de análise de consequência.

De forma geral, existe uma grande preocupação e por isso, importância em realizar análises de consequência de vazamentos e dispersão de $\mathrm{CO}_{2}$. Dentro desse contexto, neste trabalho foi utilizado o OpenFOAM para simulação de $\mathrm{CO}_{2}$ para condições de campo distante e comparados com dados da literatura.

\section{VAZAMENTO $\mathrm{CO}_{2}$}

O dióxido de carbono armazenado por estar a elevada pressão, em média, 150 bar, encontra-se na fase líquida ou super crítica. Uma ruptura em um vaso de pressão ou tubulação faria o líquido atingir pressão de saturação, entrando na região de equilíbrio, tornando-se gás. $\mathrm{O}$ alto coeficiente Joule-Thomsom e alto valor de temperatura e pressão do ponto triplo faz com que o $\mathrm{CO}_{2}$ seja um componente singular para esses estudos.

Segundo Benintendi (2014), súbita expansão faz com que a temperatura diminua de forma abrupta, atingindo temperaturas muito baixas, ocasionando formação de fase sólida (gelo seco), e possivelmente atingindo ponto triplo. O que gera uma situação singular de escoamento, escoamento multifásico levando em conta a mudança de fase entre líquido, vapor e sólido.

Com a finalidade de simulação de dispersão de gás carbono, pode-se dividir o vazamento em três etapas, como mostrado por Wen, et al. (2013). 1) Simular as condições dentro do vaso de pressão ou tubulação. 2) A partir das condições de saída da etapa 1, simular o "campo próximo" do vazamento, onde haverá formação de fases. 3) Simular o "campo 
distante" de vazamento, levando em conta só a formação de CO2 no formato de gás, e realizar a análise de consequência.

\section{MODELO MATEMÁTICO NO OPENFOAM}

Dentre os vários solvers do OpenFOAM, um que leva em consideração o balanço de componentes é o reactingFoam. Esse solver foi desenvolvido para escoamentos laminar e turbulento e leva em conta reações químicas, que podem ser desativadas para fins só de escoamento. Uma variação do reactingFoam é o rhoReactingBuoyantFOAM, que além das características do reactingFoam, levam e consideração a força do campo gavitacional e empuxo devido ao gradiente de pressão.

O modelo fundamental do rhoReactionBuoyantFoam é apresentado pelas equações de governo mostradas abaixo. A modelagem é desenvolvida utilizando a metodologia RANS (Reynolds Average Navier-Stokes), baseado em valores médios e utilizando modelos binários para simular a turbulência. No caso desse trabalho, o modelo k-epislon foi utilizado.

Conservação da Massa: 


\section{ESTUDO DE CASO}

Para estudo de dispersão de $\mathrm{CO}_{2}$, foi utilizado experimentos do projeto COOLTRANS. O COOLTRANS é um projeto iniciado em 2013 pelo governo britânico, para estudos relacionados a modos seguros de operação para transporte de $\mathrm{CO}_{2}$ em tubulações. A princípio, o trabalho foi realizado com base de publicações na literatura de Wen, Heidari, Xu, \& Jie, (2013) da Universidade de Kingston. Os autores desenvolveram um modelo para escoamento de $\mathrm{CO}_{2}$ em campo distante. $\mathrm{O}$ experimento consistiu em uma tubulação com $50 \mathrm{~mm}$ de diâmetro e $3 \mathrm{~m}$ de comprimento, posicionada no solo, na posição vertical. $\mathrm{O} \mathrm{CO}_{2}$ estava estocado a 151 bar, e temperatura $7.5^{\circ} \mathrm{C}$. A velocidade do vento no momento do experimento é de $1,79 \mathrm{~m} / \mathrm{s}$.

Para validação do OpenFOAM, foi utilizado um volume computacional de $400 \mathrm{~m}$ de comprimento, $180 \mathrm{~m}$ de largura e $200 \mathrm{~m}$ de altura. Como a tubulação no experimento possui $3 \mathrm{~m}$ em relação ao solo, e o campo distante ao escoamento foi dado como 255 diâmetros de tubulação, adicionou-se a geometria de um tubo de comprimento de $15 \mathrm{~m}$ de altura. Nesse ponto, é considerado que não há mais dióxido de carbono nas formas líquida e sólida.

O volume computacional foi feito de modo que a tubulação fique no ponto $(0,0,0)$ e a saída de gás carbono em $(0,0,15)$. Devido ao limite computacional, a malha foi adaptada com sub níveis de refinamento. As dimensões e tamanho da malha estão apresentados na Tabela 1.

Tabela 1 - Propriedades dos sistemas (fluido-partícula).

\begin{tabular}{|c|c|c|c|c|c|c|c|c|}
\hline \multirow[b]{2}{*}{ Eixo } & \multicolumn{2}{|c|}{$\begin{array}{l}\text { Vol. Computacional } \\
\qquad \Delta x^{*}=\Delta y=\Delta z=5 \mathrm{~m}\end{array}$} & \multicolumn{2}{|c|}{$\begin{array}{c}\text { Região 1 } \\
\Delta x=\Delta y=\Delta z=2,5 \mathrm{~m}\end{array}$} & \multicolumn{2}{|c|}{$\begin{array}{c}\text { Região } 2 \\
\Delta x=\Delta y=\Delta z=1,25 \mathrm{~m}\end{array}$} & \multicolumn{2}{|c|}{$\begin{array}{c}\text { Região 3 } \\
\Delta x=\Delta y=\Delta z=0,625 \mathrm{~m}\end{array}$} \\
\hline & Min & Max & Min & Max & Min & Max & Min & $\operatorname{Max}$ \\
\hline $\mathbf{x}$ & -100 & 300 & -50 & 150 & -30 & 60 & -10 & 30 \\
\hline $\mathbf{y}$ & -90 & 90 & -50 & 50 & -30 & 30 & -10 & 10 \\
\hline $\mathbf{Z}$ & 0 & 200 & 0 & 80 & 0 & 50 & 0 & 20 \\
\hline
\end{tabular}

Para ilustrar melhor as regiões de refinamento, a Figura 1 exibe a ilustração da malha computacional, vista de cima. Ao total, foram utilizadas 485.036 células computacionais. As condições na saída do vazamento foi utilizado como no artigo de Wen et al., (2013) $\square$, velocidade do vazamento $45 \mathrm{~m} / \mathrm{s}$, concentração 0,35 , temperatura a $200 \mathrm{~K}$ e pressão atmosférica. 
Figura 1 - Malha do domínio computacional, como detalhada na Tabela 1.

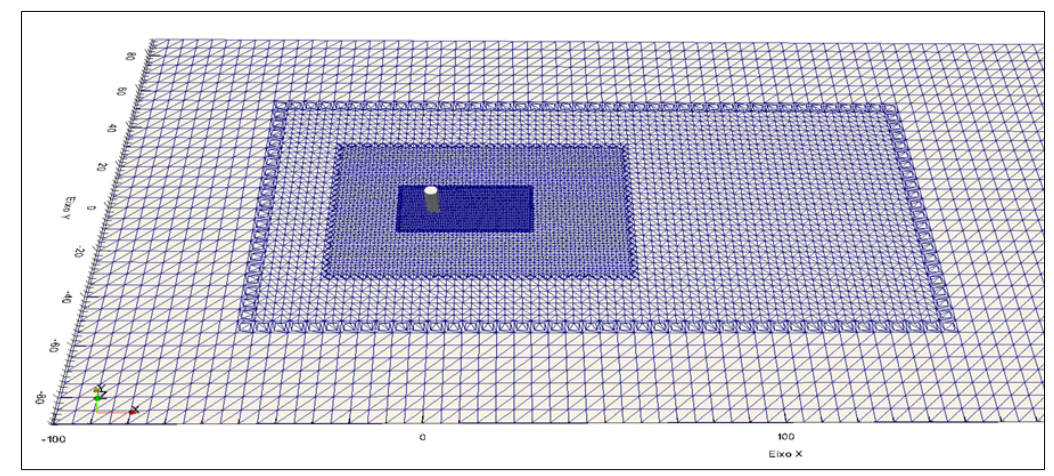

\section{RESULTADOS}

Simulação do caso experimental foi realizada com as condições citadas na seção anterior. A Figura 2 mostra o início do vazamento e a formação da nuvem de dióxido de carbono para concentração de 0,02 em fração mássica.

Figura 2 - Iso-superfície do vazamento de $\mathrm{CO}_{2}$ para concentração de $2 \%$.

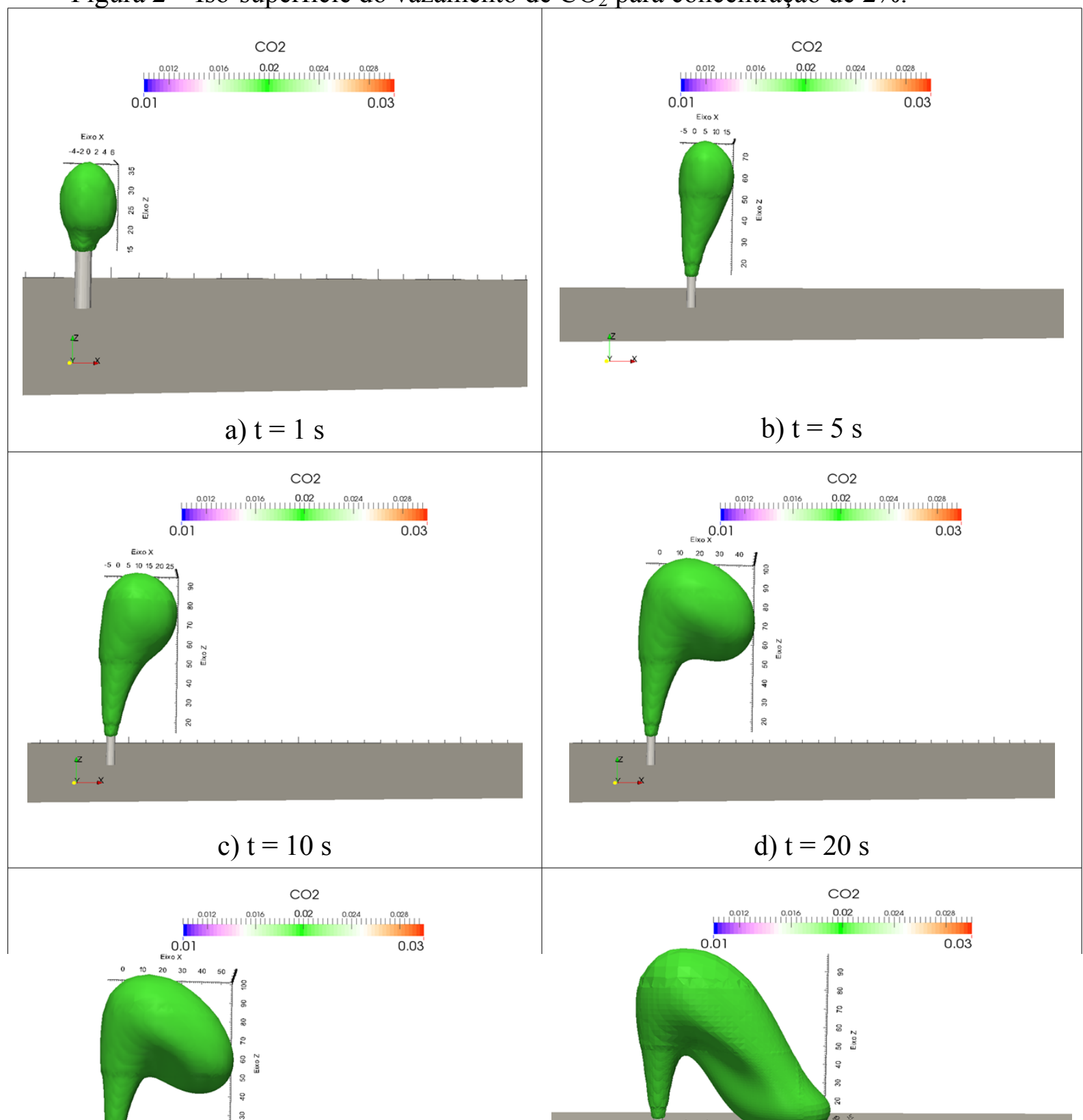


Devido a alta velocidade de vazamento $(45 \mathrm{~m} / \mathrm{s})$ comparado a velocidade do vento na direção $x$ de $1,79 \mathrm{~m} / \mathrm{s}$ o gás chega a atingir altura de $75 \mathrm{~m}$. Nos primeiros $10 \mathrm{~s}$ percebe-se que a pluma é governada pela difusão e velocidade do vento, criando uma ligeira variação no sentido $\mathrm{x}$.

Como esperado, após atingir o ápice, a nuvem tende a descer, pois o dióxido de carbono apresenta densidade 1,52 vezes maior que a densidade do ar nessa temperatura ambiente, 280 K.

\section{CONCLUSÃO}

Neste trabalho teve-se como objetivo aplicar o pacote gratuito OpenFOAM para simulação de vazamento de $\mathrm{CO}_{2}$ para campo distante, com a finalidade de demonstrar que a ferramenta computacional possui aplicabilidade para estudos de análise de risco. Foi realizada uma simulação com condições de vazamento retirados da literatura para servir de exemplo.

No que se diz respeito ao OpenFOAM, o software possui código aberto e gratuito e apresenta um solver de CFD para escoamentos reativos que foi adaptado para não realizar reações e simular o vazamento de $\mathrm{CO}_{2}$. Embora a validação com dados experimentais esteja em andamento, os resultados preliminares e qualitativos mostraram boa concordância com o esperado.

7. REFERÊNCIAS

BENINTENDI, R. (2014). Non-equilibrium phenomena in carbon dioxide expansion. Process Safety and Environmental Protection, 92(1), 47-59.

HARPER, P., WILDAY, J., \& BILIO, M. (2011). Assessment of the major hazard potential of carbon dioxide (CO2). Health and Safety Executive, 1-28. Retrieved from

MAZZOLDI, A., HILL, T., \& COLLS, J. J. (2011). Assessing the risk for CO2 transportation within CCS projects, CFD modelling. International Journal of Greenhouse Gas Control, 5(4), 816-825.

WEN, J., HEIDARI, A., XU, B., \& JIE, H. (2013). Dispersion of carbon dioxide from vertical vent and horizontal releases--A numerical study. Proceedings of the Institution of Mechanical Engineers, Part E: Journal of Process Mechanical Engineering, 227(2), 125-139. 